\title{
Orally active prostacyclin analogue beraprost sodium in patients with chronic kidney disease: a randomized, double-blind, placebo-controlled, phase II dose finding trial
}

\author{
Akio Koyama ${ }^{1 *}$, Toshiro Fujita ${ }^{2}$, Fumitake Gejyo ${ }^{3}$, Hideki Origasa ${ }^{4}$, Masanao Isono ${ }^{5}$, Hajimu Kurumatani ${ }^{5}$,
} Kiyonobu Okada ${ }^{5}$, Hiroyuki Kanoh ${ }^{6}$, Takashi Kiriyama ${ }^{6}$ and Shunsuke Yamada ${ }^{6}$

\begin{abstract}
Background: Evidence increasingly points to the importance of chronic hypoxia in the tubulointerstitium as a final common pathway to end-stage renal disease (ESRD). Beraprost sodium (BPS) is an orally active prostacyclin $\left(\mathrm{PGI}_{2}\right)$ analogue demonstrating prevention of the progression of chronic kidney disease (CKD) in various animal models by maintaining renal blood flow and attenuating renal ischemic condition.

Methods: This multicenter, randomized, double-blind, placebo-controlled, phase II trial was designed to determine the recommended dose of the sustained-release form of BPS (TRK-100STP $120 \mu \mathrm{g} /$ day or $240 \mu \mathrm{g} / \mathrm{day}$ ) in Japanese patients with CKD. TRK-100STP was administered to a total of 112 patients. The primary efficacy endpoint was the difference in the slope of the regression line of reciprocal of serum creatinine $(1 / \mathrm{SCr})$ over time, obtained by the least-squares method.
\end{abstract}

Results: Regarding the primary endpoint, statistical superiority of TRK-100STP $240 \mu \mathrm{g}$ over placebo was not confirmed and so a recommended dose was not determined. Compared to placebo, however, the slope of regression line of $1 / \mathrm{SCr}$, elevation of $\mathrm{SCr}$ and serum cystatin $\mathrm{C}$ during the treatment period revealed greater improvement at $120 \mu \mathrm{g}$, at both doses, and at $240 \mu \mathrm{g}$, respectively. In terms of safety, both TRK-100STP treatment groups were well tolerated.

Conclusions: Although the study failed to meet the primary endpoint, results indicate that TRK-100STP may potentially prevent the decline in renal function of CKD patients independent of blood pressure or urinary protein levels.

Trial registration: NCT02480751. June 21, 2015.

Keywords: Beraprost sodium, Prostacyclin analogue, CKD, TRK-100STP, Phase II trial

\section{Background}

An increasing number of patients with end-stage renal disease (ESRD) require dialysis or transplantation. Although diabetic nephropathy is a major reason for eventual ESRD, primary glomerular diseases and nephrosclerosis still comprise significant proportions of chronic kidney disease (CKD) patients, especially in Asian countries [1-4].

\footnotetext{
* Correspondence: koyama.akio.dy@alumni.tsukuba.ac.jp

'University of Tsukuba, 1-1-1 Tennodai, Tsukuba, Ibaraki 305-8577, Japan

Full list of author information is available at the end of the article
}

Angiotensin-converting enzyme inhibitors (ACEIs) and angiotensin-II receptor blockers (ARBs) are often administered to both diabetic and non-diabetic nephropathy patients, and are established as recommended treatment agents for non-diabetic nephropathy patients with albumin excretion [5]. However, it is evident that these agents are insufficient for the prevention of progressive renal disease. In addition, the use of combination therapy of renin-angiotensin system (RAS) inhibitors such as ACEI and ARB has demonstrated in some recent clinical trials to be not effective [6-9]. These findings suggest an urgent 
clinical need for a new treatment option able to significantly delay the progression of CKD.

Prostacyclin $\left(\mathrm{PGI}_{2}\right)$ is primarily synthesized in endothelial cells and one of the important functions is to protect kidneys from ischemic damage in pathophysiological conditions [10], as evidenced, for example, by the development of renal impairment in prostacyclin synthase knockout mice [11]. Attempts have been made to use $\mathrm{PGI}_{2}$ or its analogues in patients with kidney disease; the $\mathrm{PGI}_{2}$ analogue iloprost was successfully used for patients with contrast media-induced nephropathy [12].

Beraprost sodium (BPS) is an orally active $\mathrm{PGI}_{2}$ analogue [13] and TRK-100STP is its sustained-release form [14]; both were generated and developed by Toray Industries, Inc. In Asian countries, the immediaterelease form of BPS has been widely used in the treatment of patients with chronic arterial occlusion and pulmonary arterial hypertension [15].

Recent evidence increasingly points to the importance of chronic hypoxia especially in the tubulointerstitium as a final common pathway to the progression of CKD [16-20]. BPS prevents the progression of CKD in various animal models [21-24] by maintaining renal microvasculature and blood flow $[25,26]$. In addition, it is reported that BPS is effective in Acute Kidney Injury such as contrast nephropathy and cisplatin nephropathy $[27,28]$. These effects of BPS are thought to be based on multiple mechanisms of actions: direct protective effect on vascular endothelial cells [29]; inhibition of the production of inflammatory cytokines from monocyte/macrophages [23]; vasodilative [30] and antiplatelet effects [31]. The effects of BPS have also been assessed in two studies in patients with glomerulonephritis $[32,33]$. Although these studies were open-label and did not have control group, the results of one study suggested that BPS mitigates the progression rate of renal dysfunction [32,33] by increasing renal blood flow without glomerular hyperfiltration.

The efficacy of BPS on diabetic nephropathy has also been reported in several clinical [34] and non-clinical studies [35-37]; however, several methodological limitation are evident with regards to the involvement of both diabetic and non-diabetic CKD patients in a single protocol. Given the evident unmet need for non-diabetic nephropathy treatment in Asia and considering that much of the non-clinical data on BPS has been generated in non-diabetic CKD, the priority and focus of the present study was on non-diabetic CKD, given that renal disorders are not modified by diabetes. This is the first randomized, placebo-controlled, double-blind, comparative trial to investigate the recommended dose at which TRK-100STP suppresses the progression of CKD in patients with primary glomerular disease or nephrosclerosis.

\section{Methods}

This multicenter, randomized, double-blind placebocontrolled, phase II trial was designed to determine the recommended dose of TRK-100STP (i.e., either $120 \mu \mathrm{g} / \mathrm{day}$ or $240 \mu \mathrm{g} /$ day) for suppressing progression in Japanese patients with primary glomerular disease or nephrosclerosis. The study was approved by each participating center's local Research Ethics Committee. Only patients with written informed consent were included (Please refer to the list of participating centers at the end of the paper).

\section{Study design}

A summary of the study method is presented in Fig. 1. After the run-in period, when placebo tablets were orally

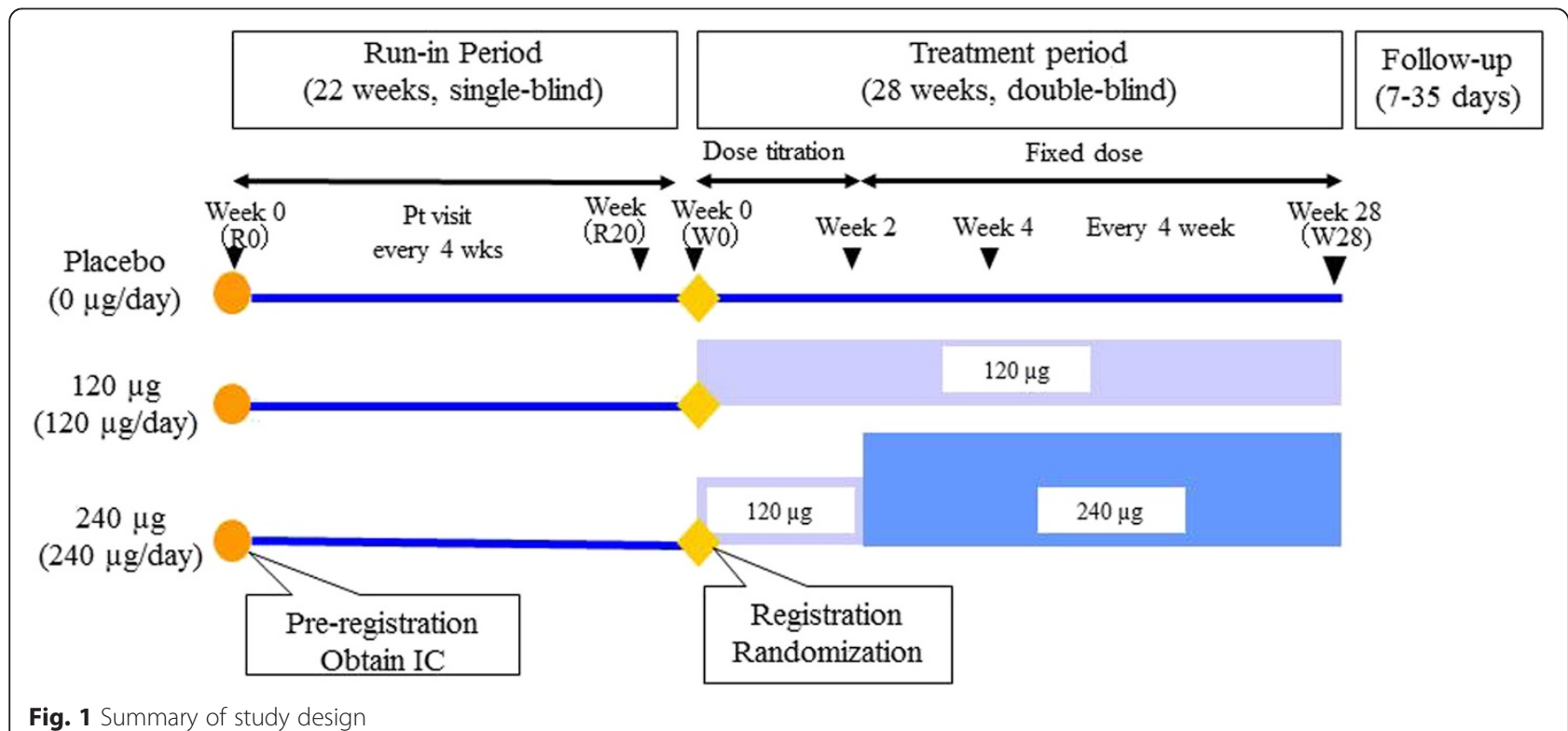


Inclusion criteria

Patients with chronic renal failure associated with primary glomerular disease or nephrosclerosis who met

the following criteria were included.

At the time of pre-registration:

1. Patients between 20 and 79 years of age at the time of consent.

2. Patients who gave written consent.

3. Patients with progressive chronic kidney disease (as a general rule, patients with reciprocal of serum creatinine $(1 / \mathrm{SCr})$ versus time slope was $\leq-0.005 \mathrm{dL} / \mathrm{mg}$ over 4 weeks were selected using all $\mathrm{SCr}$ data collected within one year before obtaining consent. The slope of the regression line was calculated for each patient by applying the least-squares equation).

At the time of registration

4. Patients with $\mathrm{CCr}$ (urinalysis with 24-hour pooled urine samples) at Week 20 (R20) of the run-in period exceeding $15.0 \mathrm{~mL} / \mathrm{min}$.

5. Patients with $\mathrm{SCr}$ at Week 20 (R20) of the run-in period between $1.30-4.00 \mathrm{mg} / \mathrm{dL}$ for women and $1.50-4.50 \mathrm{mg} / \mathrm{dL}$ for men.

6. Patients with $1 / \mathrm{SCr}$ versus time slope was $\leq-0.005 \mathrm{dL} / \mathrm{mg}$ over 4 weeks calculated from all $\mathrm{SCr}$ data collected up to Week 20 (R20) of the run-in period. The slope of the regression line was calculated for each patient by applying the least-squares equation.

7. Patients with measures of SCr levels up until Week 20 (R20) of the run-in period between $50-200 \%$ of the $\mathrm{SCr}$ levels measured at Week 0 (R0) of the run-in period.

Exclusion criteria

Patients were excluded if they met any of the following criteria.

At the time of pre-registration:

1. Patients with secondary glomerular disease associated with lupus nephritis, hereditary nephritis (Alport syndrome), or other diseases.

2. Patients with chronic renal failure associated with primary pyelonephritis, primary tubulointerstitial nephritis, primary gouty nephropathy, primary cystic kidney disease, or primary nephrolithiasis/urolithiasis.

3. Patients with diabetes mellitus.

4. Patients with a history of renal transplantation, hemodialysis, or continuous ambulatory peritoneal dialysis (CAPD).

5. Patients with a comorbid urinary tract infection.

6. Patients with comorbid nephrotic syndrome.

7. Patients who experienced chronic bleeding (from hemophilia, capillary fragility, gastrointestinal bleeding, urinary tract bleeding, hemoptysis, fundal hemorrhage, and other causes), or those patients with bleeding tendency, with the exception of transient bleeding, such as epistaxis/nasal bleeding, menstrual bleeding, gingival bleeding, and hemorrhoidal bleeding.

8. Patients suffering from malignant hypertension or poorly-controlled hypertension (systolic blood pressure $\geq 150 \mathrm{mmHg}$ or diastolic blood pressure $\geq 95 \mathrm{mmHg}$ at rest, measured at all three evaluation points immediately before obtaining consent).

9. Patients with comorbid malignancy

10. Patients suffering from serious hepatic diseases, hematologic diseases, respiratory diseases, digestive system diseases, cardiac diseases, or encephalopathy.

11. Patients who experienced allergic reactions to BPS.

12. Patients who had taken another investigational drug or a post-marketing study drug within the six months before obtaining consent.

13. Patients who were pregnant, nursing, or those who wished to become pregnant during the study period.

14. Patients who had a history of illicit drug or alcohol abuse.

15. Patients who exhibited poor self-management behaviors, such as those involving diet and medication.

16. Other patients who were determined by the principal investigator or a sub investigator as being unsuitable for participating in the study.

At the time of registration, measures were taken to ensure that none of the patients met any of the exclusion criteria (1) through (16) that were set at pre-registration. At the time of registration, however, the exclusion criteria (3) and (8) set at pre-registration were revised as follows:

3. Patients with comorbid diabetes mellitus or those with $\mathrm{HbAlC}$ levels of $6.5 \%$ or higher.

8. Patients suffering from malignant hypertension or poorly-controlled hypertension (systolic blood pressure $\geq 150 \mathrm{mmHg}$ or diastolic blood pressure $\geq 95 \mathrm{mmHg}$ measured while the patient is sitting at rest.

The measurements must be consistent at all three consecutive evaluation points during the run-in period).

Fig. 2 Inclusion and exclusion cliteria 
administered twice daily for 22 weeks in a single-blinded manner, patients who met all of the inclusion criteria and none of the exclusion criteria (detailed in Fig. 2) were randomized into one of the three treatment groups (TRK100STP $120 \mu \mathrm{g}, 240 \mu \mathrm{g}$ or placebo group) using computer random number generator to select random permuted blocks. Central randomization was performed by external statistician for the 28-week treatment period in a doubleblinded manner. Enrollment to the trial was restricted to patients whose renal function had progressively declined during the 22-week run-in period ( $R 0 \sim \mathrm{R} 20$ ) to obtain adequate treatment response data during the 28-week treatment period (W0 W28).

Reciprocal of serum creatinine $(1 / \mathrm{SCr})$ versus time slope shows the speed of renal function decline so that this parameter is used to estimate how long it will take to start dialysis and to evaluate therapeutic effects [38]. This parameter is used for example to show the status of nephropathy in the RENAAL trial [39].

Therefore, in order to limit the participants to those with progressive diseases, only patients whose reciprocal of serum creatinine $(1 / \mathrm{SCr})$ versus time slope was $\leq-0.005 \mathrm{dL} / \mathrm{mg}$ over 4 weeks during the run-in period were randomized. This value was based on the patients' background in a trial of orally administered spherical carbon adsorbent AST-120 [40]. The primary endpoint was also $1 / \mathrm{SCr}$ versus time slope and the differences between the treatment- and the observation-period values were evaluated.

The study drug in the treatment period was orally administered twice daily, after meals, for 28 weeks in a double-blinded manner. The first 2 weeks of the treatment period were designated as the dose-titration period with respect to safety analyses. The initial dose for the TRK-100STP groups was $120 \mu \mathrm{g} /$ day. For the $240 \mu \mathrm{g}$ group, the dose was increased to $240 \mu \mathrm{g}$ /day after the 2-week dose-titration period. One follow-up assessment was performed between 7 to 35 days after completion or discontinuation of study drug during the treatment period.

The two doses of TRK-100STP $(120 \mu \mathrm{g} /$ day and $240 \mu \mathrm{g} /$ day) were selected for this trial on the basis that a $30 \mu \mathrm{g}$ single dose was considered unable to achieve the effective plasma concentration, whilst a $180 \mu \mathrm{g}$ single dose previously resulted in a higher incidence of headache and other adverse drug reactions (ADRs) in a completed phase I clinical study of TRK-100STP. Based on these observations, TRK-100STP at 60 to $120 \mu \mathrm{g}$ b.i.d. (i.e., 120 to $240 \mu \mathrm{g} /$ day) were selected for investigation in the present trial.

\section{Study endpoints}

The primary efficacy endpoint was the difference between the run-in and treatment periods in the slope of the regression line of $1 / \mathrm{SCr}$ versus time, which was calculated by the least-squares method. All SCr data collected in the run-in period $(\mathrm{R} 0 \sim \mathrm{R} 20)$ and the treatment period (W4 W28) were used for the plot in order to exclude the possible effect of the titration period (W0 W2).

Secondary endpoints were as follows: 1 ) The difference between the run-in period $(\mathrm{R} 0 \sim \mathrm{R} 20)$ and treatment period (W0 W28) in 1/SCr versus time slope; 2 ) changes in creatinine clearance (CCr, Cockcroft-Gault equation); 3) changes in $\mathrm{CCr}$ (urinalysis with 24-hour pooled urine); 4) changes in urinary protein excretion; 5) ratio of $\mathrm{SCr}$; and 6) changes in serum cystatin C. Safety endpoints were as follows: 1) adverse events (AEs); 2) clinical laboratory tests; 3) vital signs and body weight; and 4) 12-lead electrocardiogram (ECG).

\section{Prohibited and restricted concomitant medications Prohibited concomitant medications}

Use of the following medications were prohibited during the study period: spherical carbon adsorbent; prostaglandin

Table 1 Study measurements

\begin{tabular}{ll}
\hline Examination by investigator & Objective symptoms (patient interview) \\
Physical examination & Body weight, blood pressure, pulse rate, 12-lead ECG \\
Hematological examination & WBC, RBC, Hb, Ht, PLT, \\
& Differential count of leukocytes (basophil, eosinophil, neutrophil, lymphocyte, monocyte) \\
Bleeding and coagulation test & PT, APTT \\
Blood biochemistry & TP, Alb, T-BIL, AST(GOT), ALT(GPT), ALP, LDH, y-GTP, \\
& TCh, TG, UA, BUN, serum creatinine (SCr), Na, K, Cl, Ca, P, HbA1C, cystatin C, \\
& High-sensitive CRP \\
Uremia toxins test in plasma & Guanidino succinate \\
Urinalysis (occasional urine) & PH, qualitative protein, glucose, and urobilinogen, occult blood reaction urinary sediment (RBC, WBC, casts), \\
Urinalysis (24-hour pooled urine) & Urinary protein excretion, CCr, urea nitrogen, electrolytes (Na, Cl), urine output, creatinine \\
\hline
\end{tabular}




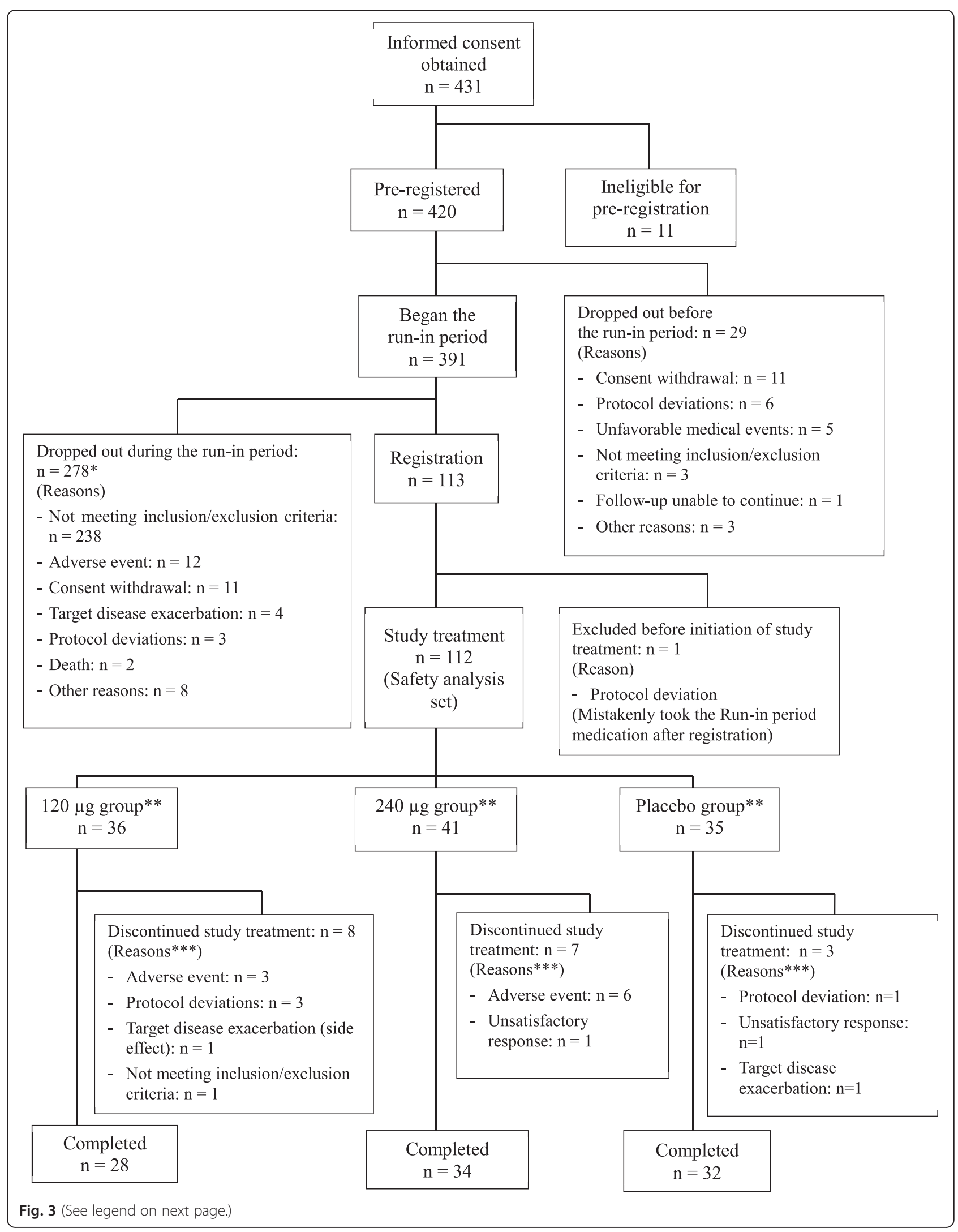


(See figure on previous page.)

Fig. 3 Patient dispositiona. aCONSORT 2010 flow diagram was provided as Additional file 1. * The number of the patients who were excluded during the Run-in period ( $n=279$ ) was calculated by adding the number of the patients who dropped out during the Run-in period ( $\mathrm{n}=278$ ) and the patient who was excluded before the initiation of the study treatment $(n=1) .{ }^{*}$ Ten patients whose SCr values measured less than three points after Week 4 of the Treatment period were excluded from 112 patients randomized. As a results, 102 patients (32 patients in the 120 $\mu \mathrm{g}$ group, 36 patients in the $240 \mu \mathrm{g}$ group and 34 patients in the placebo group) were included in the full analysis set (FAS). ${ }^{* * *}$ If there were multiple reasons for discontinuation, the main reason was used for calculation

analogues, other than eye drops and those in ointment form; antiplatelet agents, with the exception of aspirin products; anticoagulant and thrombolytic agents, except for temporary use such as for examinations; fluorinated pyrimidine antifungal agents; and iodinated radiocontrast agents.

\section{Restricted concomitant medications}

Dosage of ACEIs and ARBs were stipulated to be fixed during the study period. However, in necessary situations, such as increased serum potassium levels that did not improve with alternative options, a reduction in ACEI or ARB doses was allowed. Taking nonsteroidal anti-inflammatory drugs (NSAIDs) continuously for more than one week was prohibited.

\section{Sample size estimation}

The sample size estimation was based on a previous study, a Phase III clinical trial of AST-120 (indicated for the treatment of chronic renal failure (CRF) in Japan), conducted in a total of 237 patients (119 patients treated with the active drug and 118 received placebo) for 24 weeks [40]. The study showed that the difference in the slope of regression line of $1 / \mathrm{SCr}$ versus time of AST-120 and the placebo groups before and after treatment with the test drug was $0.00352(\mathrm{dL} / \mathrm{mg}$ over 4 weeks). Based on this value, we hypothesized that the TRK-100STP $120 \mu \mathrm{g}$ group would show efficacy similar to the AST-120 group, and that the TRK100STP $240 \mu$ g group would show 1.5 times better efficacy than the AST-120 group. According to these predictions, we set contrast coefficients $[-1,0,1]$ for the placebo, the TRK-100STP $120 \mu \mathrm{g}$, and the $240 \mu \mathrm{g}$ groups. The number of patients required per group was estimated to be 71 (with a two-sided $5 \%$ significance level and $80 \%$ statistical power). On this basis, the target number of patients needed to recruit was set at 430 patients, taking into account the possibility that the patient withdrawal rate in the run-in period might be high because of the long run-in period.

\section{Statistical analysis}

(a) Primary endpoint

Using all SCr data collected during the run-in period $(\mathrm{R} 0 \sim \mathrm{R} 20)$ and treatment period (W4 $\sim \mathrm{W} 28)$, reciprocal SCr values plotted against time were analyzed. The slopes of the regression line were calculated by applying the least-squares equation. The difference in the slopes between the run-in period $(\mathrm{R} 0 \sim \mathrm{R} 20)$ and treatment period (W4 W28) was evaluated as the primary endpoint. In order to determine the recommended dose,

Table 2 Baseline characteristics of patients in the full analysis set (FAS)

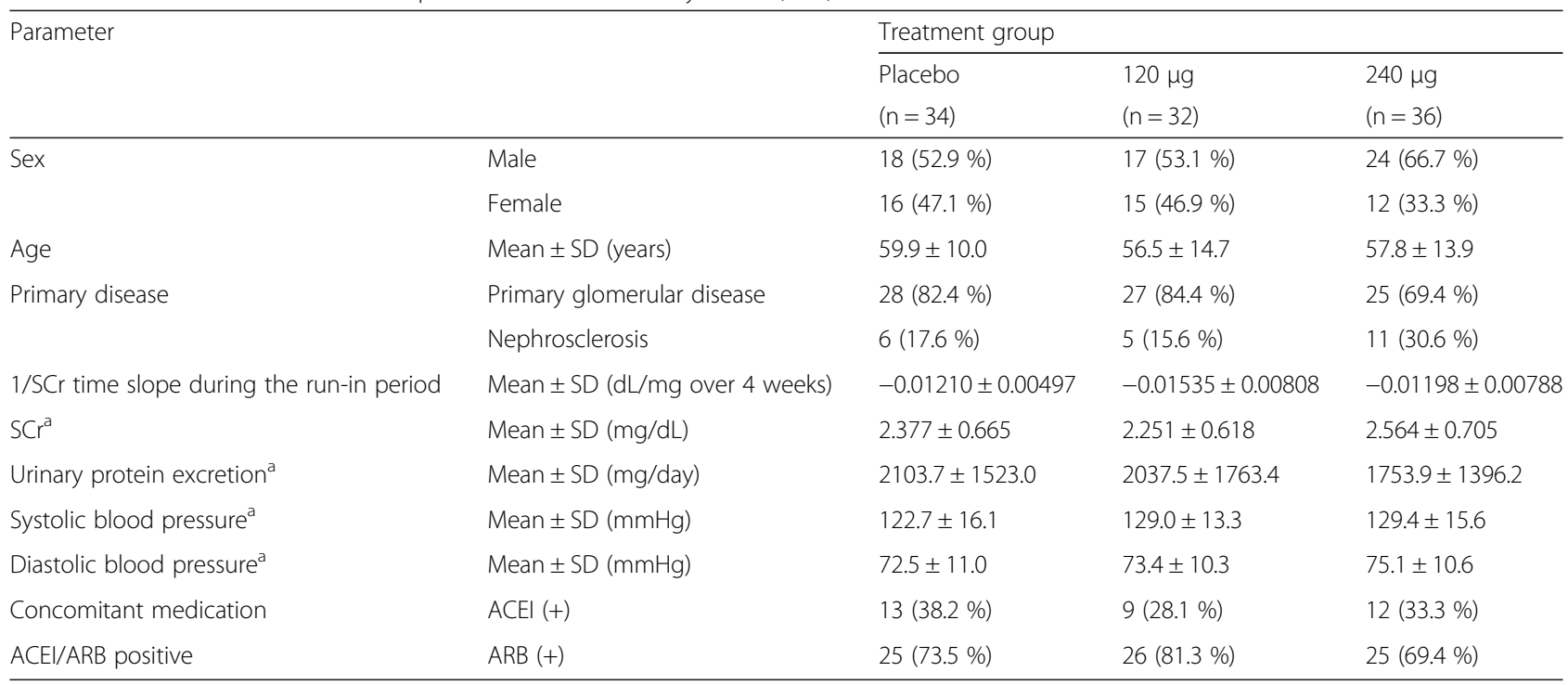

${ }^{\mathrm{a}} \mathrm{As}$ of $\mathrm{R} 20$ 


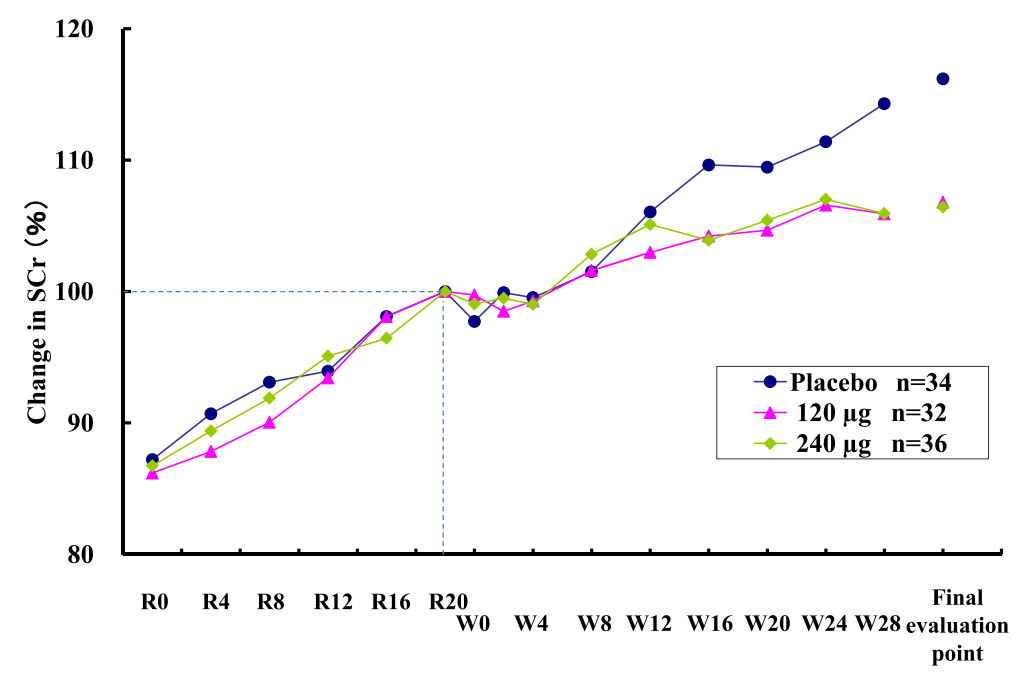

Fig. 4 Change in SCr during study period (SCr values of each group at R20 [Week 20 of the run-in period] were set as $100 \%$ )

the primary endpoint was analyzed by the following procedures:

- Step 1: Analysis of covariance (ANCOVA) with the slopes calculated from the results obtained during the run-in period as a covariate after assigning contrast coefficients $[-1,0,1]$.

- Step 2: ANCOVA with the slopes obtained from the results collected during the run-in period as a covariate after assigning contrast coefficient $[-1,1,0]$, only when a statistical significance was detected in Step 1.

(b) Secondary endpoints

Analytical methods for secondary endpoints are described in each result.

(c) Post hoc analysis

Ratio of SCr (the final evaluation point/WO)

In analyzing the ratio of $\mathrm{SCr}$ for the secondary endpoint, the $\mathrm{SCr}$ values measured at R20 were chosen as baseline as other parameters such as $\mathrm{CCr}$, urinary protein and cystatin C were measured only at R20. Regarding SCr, however, as the value at W0 measured just before the treatment period was available, the ratio of $\mathrm{SCr}$ (the final evaluation point/W0) was assessed by ANCOVA with the $\mathrm{SCr}$ (R20) as covariate.

Change in serum cystatin $C$ in the treatment period (final evaluation point - R20)

As the ratio of $\mathrm{SCr}$ was analyzed only for the treatment period, changes in cystatin $\mathrm{C}$ were re-evaluated based only on data from the treatment period.

Changes in cystatin $\mathrm{C}$ were calculated using values taken at R20 as the baseline (the final evaluation point R20). ANCOVA was performed with the SCr (R20) as the covariate. As the values at W0 were not available, the values at R20, the examination point of the study closest to W0, were used as baseline.

Ratio of eGFR (the final evaluation point/WO)

Ratio of eGFR (the final evaluation point/W0) was assessed by ANCOVA with the $\mathrm{SCr}$ (R20) as covariate. In order to calculate the eGFR for Japanese patients, the following equation was used;

$\operatorname{GFR}($ male $)=194 * \mathrm{Scr}^{-1.094 *} \operatorname{age}^{-0.287}$, and GFR $($ female $)=$ GFR(male)*0.739 [41].

\section{Study measurements}

The parameters that were measured and analyzed are listed in Table 1.

Table 3 Summary statistics of primary endpoint (the difference in the 1/SCr versus time slope between run-in period [R0 $\sim$ R20] and treatment period [W4 $\sim$ W28])

\begin{tabular}{|c|c|c|c|c|c|c|c|}
\hline \multirow[t]{3}{*}{ Treatment group } & \multirow[t]{3}{*}{ No. of patients } & \multicolumn{4}{|c|}{$1 / \mathrm{SCr}$ versus time slope (dL/mg over 4 weeks) } & \multicolumn{2}{|c|}{$\begin{array}{l}\text { Difference in the } 1 / \mathrm{SCr} \text { versus } \\
\text { time slope (dL/mg over } 4 \text { weeks) }\end{array}$} \\
\hline & & \multicolumn{2}{|c|}{ Run-in period (R0 R20) } & \multicolumn{2}{|c|}{ Treatment period (W4 W28) } & \multirow[b]{2}{*}{ Mean } & \multirow[b]{2}{*}{ SD } \\
\hline & & Mean & SD & Mean & SD & & \\
\hline Placebo & 34 & -0.0121 & 0.00497 & -0.0074 & 0.00935 & 0.0047 & 0.01087 \\
\hline $120 \mu \mathrm{g}$ & 32 & -0.0154 & 0.00808 & -0.0040 & 0.01345 & 0.0113 & 0.01011 \\
\hline $240 \mu \mathrm{g}$ & 36 & -0.0120 & 0.00788 & -0.0045 & 0.00750 & 0.0075 & 0.00953 \\
\hline
\end{tabular}




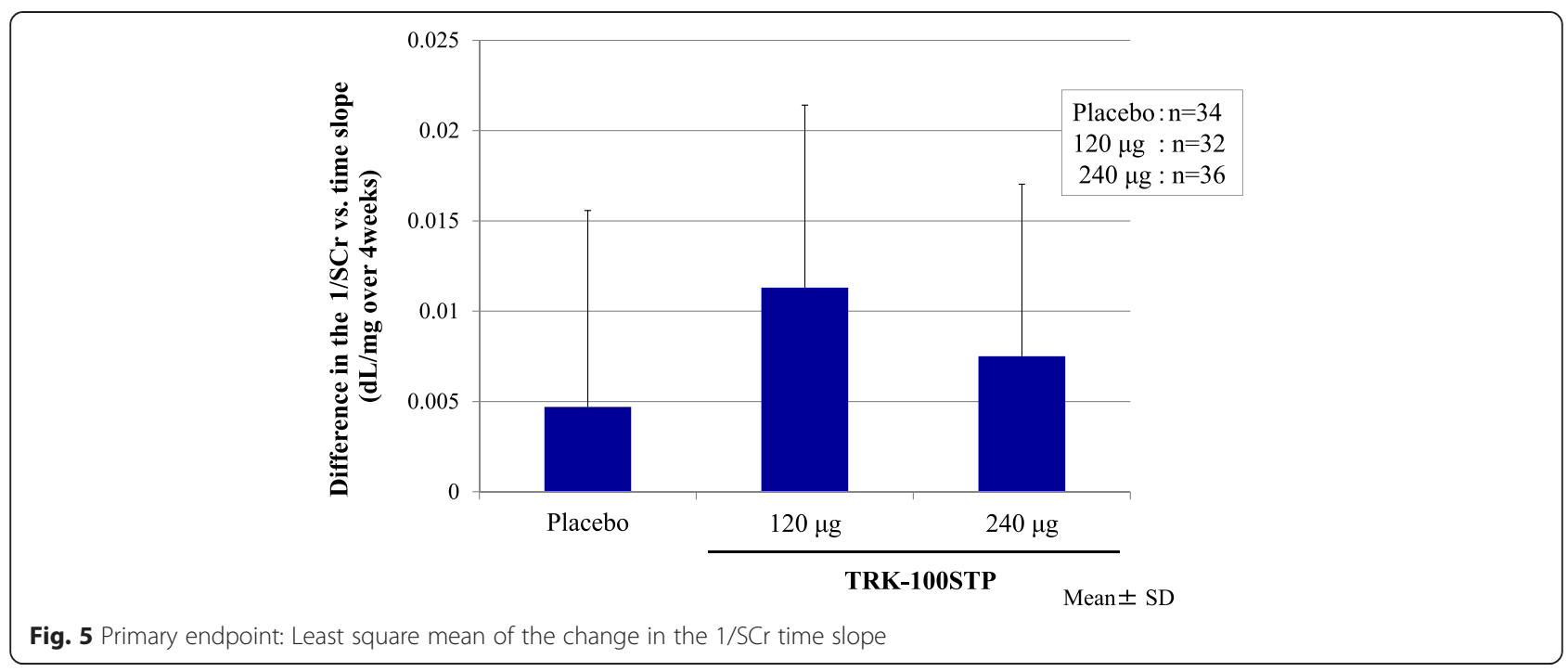

Trial registration

NCT02480751. June 21, 2015.

\section{Results}

\section{Patient disposition}

The trial began on October 24, 2005 (the date the first consent was obtained) and was completed on May 20, 2008 (the last follow-up date of the final patient).

A summary of the patient disposition is described in Fig. 3. Written informed consents were obtained from a total of 431 patients, 11 of whom did not meet the criteria on pre-registration and a total of 420 patients were preregistered. Of these 420 patients, 29 dropped out before the start of the run-in period and a further 278 patients were withdrawn during the run-in period or at the registration. A total of 113 patients were therefore registered, of which one patient, who mistakenly took the run-in period medication and did not take the study drug for the treatment period after the registration, was excluded from the study. As a result, the study drugs were administered to a final total of 112 patients (35 patients in the placebo group, 36 patients in the $120 \mu$ g group and 41 patients in the $240 \mu \mathrm{g}$ group) in a double-blind manner. Most of 238 patients who did not meet the inclusion/exclusion criteria before registration were excluded because their renal failure progressed at a slower rate during the run-in period, represented by a $1 / \mathrm{SCr}$ versus time slope of $\leq$ $-0.005 \mathrm{dL} / \mathrm{mg}$ over 4 weeks.

\section{Analysis sets}

Ten patients whose SCr values measured less than three points after Week 4 of the treatment period were excluded from 112 patients randomized. As a result, 102 patients (34 patients in the placebo group, 32 patients in the $120 \mu \mathrm{g}$ group and 36 patients in the $240 \mu \mathrm{g}$ group) were included in the full analysis set (FAS). From FAS, four patients were excluded whose SCr values measured after Week 4 of the treatment period were less than 5 points. The remaining patients constituted the per protocol set (PPS). PPS therefore consisted of 98 patients (34 patients in the placebo group, 29 patients in the $120 \mu$ g group and 35 patients in the $240 \mu \mathrm{g}$ group). The safety analysis set consisted of 112 patients (35 patients in the placebo group, 36 patients in the $120 \mu$ group and 41 patients in the $240 \mu$ g group), who received the study drug for the treatment period.

Demographic and other baseline characteristics of patients in the FAS are presented in Table 2. Baseline characteristics of patients were not significantly different

Table 4 Difference in the 1/SCr versus time slope between run-in period (RO R20), and Treatment period (W4 W28) analyzed by the ANCOVA model: comparison of the TRK-100STP groups versus placebo

\begin{tabular}{|c|c|c|c|c|c|c|}
\hline \multirow[t]{2}{*}{ Treatment group } & \multirow[t]{2}{*}{ No. of patients } & \multicolumn{2}{|c|}{$\begin{array}{l}\text { Least square mean of the change in } \\
\text { the } 1 / \mathrm{SCr} \text { slope }\end{array}$} & \multicolumn{2}{|c|}{$\begin{array}{l}\text { Difference in the least square mean } \\
\text { (versus placebo) }^{a}\end{array}$} & \multirow{2}{*}{$\begin{array}{l}\text { Contrast test } \\
\text { ( } P \text { value }) \\
(-1,0,1)\end{array}$} \\
\hline & & Point estimate & $95 \% \mathrm{Cl}$ & Point estimate & $95 \% \mathrm{Cl}$ & \\
\hline Placebo & 34 & 0.00516 & {$[0.00187,0.00845]$} & - & - & \\
\hline $120 \mu \mathrm{g}$ & 32 & 0.01026 & {$[0.00682,0.01369]$} & 0.00510 & {$[0.00031,0.00989]$} & \\
\hline $240 \mu \mathrm{g}$ & 36 & 0.00798 & {$[0.00478,0.01118]$} & 0.00282 & {$[-0.00175,0.00740]$} & 0.2234 \\
\hline
\end{tabular}

a $(120 \mu \mathrm{g}$ group or $240 \mu \mathrm{g}$ group) - (placebo group)

$1 / \mathrm{Scr}$ versus time slope during the run-in period as the covariate 
Table 5 Ratio of SCr [the final evaluation point ${ }^{\mathrm{a}} /$ WO (week 0 of the treatment period)] analyzed by the ANCOVA model

\begin{tabular}{|c|c|c|c|c|c|c|}
\hline \multirow[t]{2}{*}{$\begin{array}{l}\text { Treatment } \\
\text { group }\end{array}$} & \multirow[t]{2}{*}{$\begin{array}{l}\text { Number } \\
\text { of } \\
\text { patients }\end{array}$} & \multicolumn{2}{|c|}{$\begin{array}{l}\text { Least square mean } \\
\text { of the ratio of } \mathrm{SCr}\end{array}$} & \multicolumn{2}{|c|}{$\begin{array}{l}\text { Difference in the } \\
\text { least square mean } \\
\text { (versus placebo) }\end{array}$} & \multirow[t]{2}{*}{ P-value } \\
\hline & & $\begin{array}{l}\text { Point } \\
\text { estimate }\end{array}$ & SE & $\begin{array}{l}\text { Point } \\
\text { estimate }\end{array}$ & SE & \\
\hline Placebo & 34 & 1.169 & 0.032 & - & - & - \\
\hline $120 \mu \mathrm{g}$ & 32 & 1.069 & 0.033 & 0.100 & 0.045 & 0.0309 \\
\hline $240 \mu \mathrm{g}$ & 36 & 1.064 & 0.031 & 0.105 & 0.044 & 0.0204 \\
\hline
\end{tabular}

${ }^{a} A t$ Week 28 of the treatment period or when treatment was discontinued

*ANCOVA with baseline ( $\mathrm{SCr}(\mathrm{R} 20))$ as covariate

among the treatment groups. It is noteworthy that $69 \%$ to $81 \%$ of patients were taking ARB in each group.

\section{Changes in $\mathrm{SCr}$}

Figure 4 illustrates the changes in SCr through the study periods when $\mathrm{SCr}$ values of each group at R20 were set at $100 \%$. The $\mathrm{SCr}$ values in all three groups increased during the run-in and treatment periods, and increases in $\mathrm{SCr}$ values in the treatment period tends to be suppressed in the two TRK-100STP groups.

\section{Efficacy}

As the primary analysis set is also the FAS, the data and the results of evaluation are described based on the FAS, whilst the efficacy analysis was performed in both the FAS and PPS.

(a) Primary endpoint
The difference in the $1 / \mathrm{SCr}$ versus time slope between the run-in period $(R O \sim R 20)$ and the treatment period (W4 $\sim$ W28)

As shown in Table 3 and Fig. 5, compared with the run-in period, a slight improvement in the $1 / \mathrm{SCr}$ versus time slope was observed during the treatment period in all treatment groups; this tendency was clearly observed in patients of the TRK-100STP $120 \mu$ g group.

Table 4 shows the result of ANCOVA with the $1 / \mathrm{SCr}$ versus time slope during the run-in period as the covariate. No statistically significant difference was observed between the $240 \mu \mathrm{g}$ group and the placebo group when the ANCOVA was performed with the contrast coefficients of $[-1,0,1]$ for [the placebo group, the $120 \mu \mathrm{g}$ group, and the $240 \mu \mathrm{g}$ group] $(P=0.2234)$.

(b) Secondary endpoints

The difference in the $1 / \mathrm{SCr}$ versus time slope between the run-in period $(R O \sim R 20)$ and the treatment period (WO $\sim$ W28)

The least square mean of the difference in the $1 / \mathrm{SCr}$ versus time slope [95\% CI] was $0.00590 \mathrm{dL} / \mathrm{mg}$ over 4 weeks [0.00308, 0.00873] in the placebo group, $0.01065 \mathrm{dL} /$ mg over 4 weeks $[0.00769,0.01360]$ in the TRK-100STP $120 \mu \mathrm{g}$ group and $0.00801 \mathrm{dL} / \mathrm{mg}$ over 4 weeks [0.00525, 0.01076] in the $240 \mu \mathrm{g}$ group. Moreover, ANCOVA was performed on the same model as the primary endpoint with the contrast coefficients of $[-1,0,1],[-1,1,0],[-1,-1,2]$, and $[-2,1,1]$ for the placebo group, the $120 \mu \mathrm{g}$ group, and the $240 \mu \mathrm{g}$ group, respectively. The results of ANCOVA with contrast coefficients of $[-1,0,1],[-1,1,0]$, $[-1,-1,2]$ and $[-2,1,1]$ were $P=0.2912, P=0.0244$, $P=0.8764$ and $P=0.0534$, respectively. Thus the $120 \mu \mathrm{g}$

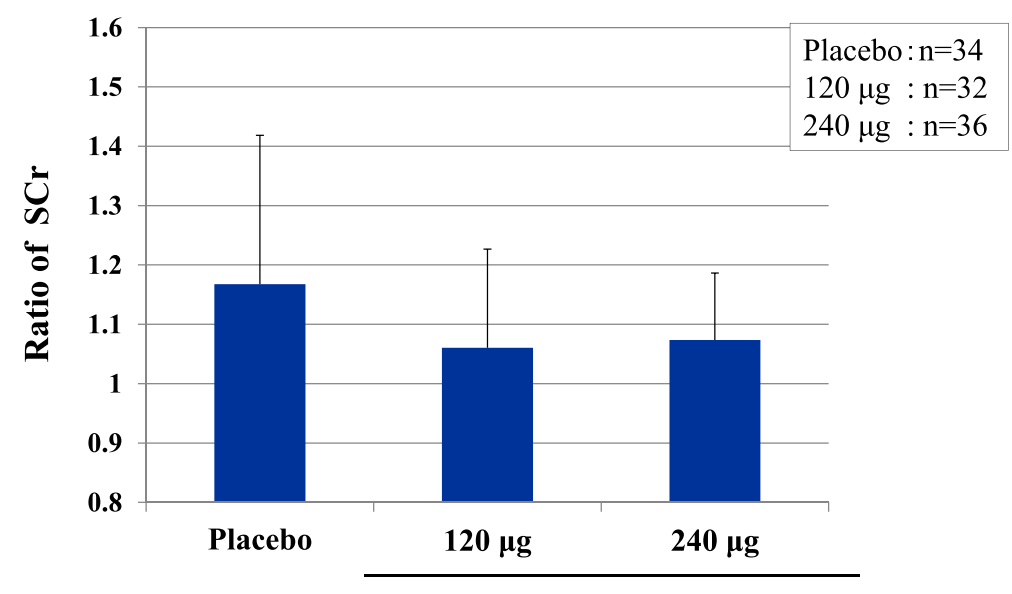

TRK-100STP

Mean \pm SD

Fig. 6 Mean $\pm S D$ of ratio of SCr (final evaluation point/W0 [week 0 of the treatment period]): As shown in Table 5, both the 120 $\mu$ g and the $240 \mu \mathrm{g}$ groups showed an inhibition of the increase in SCr ratios as compared with the placebo group $(P=0.0309,0.0204$, respectively), assessed by ANCOVA with the SCr (R20) as covariate 
Table 6 Changes in serum cystatin C [the final evaluation point ${ }^{a}$-R20 (week 20 of the Run-in period)] comparison of TRK-100STP groups versus placebo analyzed by the ANCOVA model

\begin{tabular}{|c|c|c|c|c|c|c|}
\hline \multirow[t]{2}{*}{$\begin{array}{l}\text { Treatment } \\
\text { group }\end{array}$} & \multirow[t]{2}{*}{$\begin{array}{l}\text { Number } \\
\text { of } \\
\text { patients }\end{array}$} & \multicolumn{2}{|c|}{$\begin{array}{l}\text { Least square mean } \\
\text { of the difference } \\
\text { in serum cystatin C } \\
\text { (mg/L) }\end{array}$} & \multicolumn{2}{|c|}{$\begin{array}{l}\text { Difference in the } \\
\text { least square mean } \\
\text { (versus placebo) } \\
\text { (mg/L) }\end{array}$} & \multirow[t]{2}{*}{ P-value } \\
\hline & & $\begin{array}{l}\text { Point } \\
\text { estimate }\end{array}$ & SE & $\begin{array}{l}\text { Point } \\
\text { estimate }\end{array}$ & SE & \\
\hline Placebo & 32 & 0.253 & 0.065 & - & - & - \\
\hline $120 \mu \mathrm{g}$ & 31 & 0.097 & 0.066 & 0.157 & 0.092 & 0.0928 \\
\hline $240 \mu \mathrm{g}$ & 35 & 0.052 & 0.063 & 0.201 & 0.090 & 0.0285 \\
\hline
\end{tabular}

${ }^{a}$ At Week 28 of the treatment period or when treatment was discontinued

${ }^{b}$ Different from FAS because some patients lacked value of cystatin C

group showed a significant amelioration compared with the placebo group (contrast coefficients: $[-1,1,0]: P=0.0244$ ).

Changes in $\mathrm{CCr}$

The difference in the change of $\mathrm{CCr}$ in urinalysis with 24-hour pooled urine sample (the change in the treatment period [the final evaluation point - R20]) was $1.08 \pm$ $9.35 \mathrm{~mL} / \mathrm{min}$ in the placebo group (mean $\pm \mathrm{SD}$ ), $6.16 \pm$ $11.22 \mathrm{~mL} / \mathrm{min}$ in the TRK-100STP $120 \mu \mathrm{g}$ group and $3.94 \pm 7.80 \mathrm{~mL} / \mathrm{min}$ in the $240 \mu \mathrm{g}$ group. Both TRK100STP groups therefore showed a tendency of inhibiting the decline in $\mathrm{CCr}$ as compared with the placebo group ( $P=0.0551, P=0.1800$ : $t$-test). When $C C r$ was calculated with the Cockcroft-Gault equation, the change in the treatment period (the final evaluation point - R20) was $2.03 \pm 5.98 \mathrm{~mL} / \mathrm{min}$ in the placebo group (mean \pm $\mathrm{SD}), 3.93 \pm 5.30 \mathrm{~mL} / \mathrm{min}$ in the TRK-100STP $120 \mu \mathrm{g}$ group and $3.77 \pm 5.06 \mathrm{~mL} / \mathrm{min}$ in the $240 \mu \mathrm{g}$ group. Both TRK-
100STP groups therefore showed a tendency of inhibiting the decline in $\mathrm{CCr}$ as compared with the placebo group $(P=0.1771, P=0.1917: t$-test $)$.

\section{Changes in urinary protein excretion}

The change in urinary protein excretion (the final evaluation point - R20) was $121.59 \pm 715.60 \mathrm{mg} /$ day in the placebo group, $241.68 \pm 849.23 \mathrm{mg} /$ day in the TRK100STP $120 \mu \mathrm{g}$ group and $280.38 \pm 817.97 \mathrm{mg} /$ day in $240 \mu \mathrm{g}$ group. It was shown that the observed change in the urinary protein excretion in the $120 \mu \mathrm{g}$ and $240 \mu \mathrm{g}$ groups (versus the placebo group) was small relative to the standard deviation, and both TRK-100STP groups showed no significant difference compared to the placebo group ( $P=0.5457, P=0.4056$ : $t$-test).

\section{Ratio of $\mathrm{SCr}$}

The ratio of $\mathrm{SCr}$ (the final evaluation point/R20) was $1.14 \pm 0.27$ in the placebo group, $1.06 \pm 0.20$ in the TRK100STP $120 \mu \mathrm{g}$ group and $1.06 \pm 0.13$ in the $240 \mu \mathrm{g}$ group. Although both TRK-100STP groups did not show any significant inhibition, they showed a tendency of inhibiting the increase in $\mathrm{SCr}$ as compared with the placebo group $(P=0.1379, P=0.0942$ : $t$-test $)$.

Changes in serum cystatin $C$

The difference in the change in serum cystatin $C$ (the change in the treatment period [the final evaluation point - R20] - the change in the Run-in period [R20 R0]) was $0.155 \pm 0.448 \mathrm{mg} / \mathrm{L}$ in the placebo group, $0.006 \pm 0.377 \mathrm{mg} / \mathrm{L}$ in the TRK-100STP $120 \mu \mathrm{g}$ group, and $-0.023 \pm 0.645 \mathrm{mg} / \mathrm{L}$ in the $240 \mu \mathrm{g}$ group. Both TRK-100STP groups therefore showed a tendency of inhibiting the increase in serum cystatin $\mathrm{C}$ as compared versus the placebo group $(P=0.1588, P=0.1973$ : $t$-test $)$.

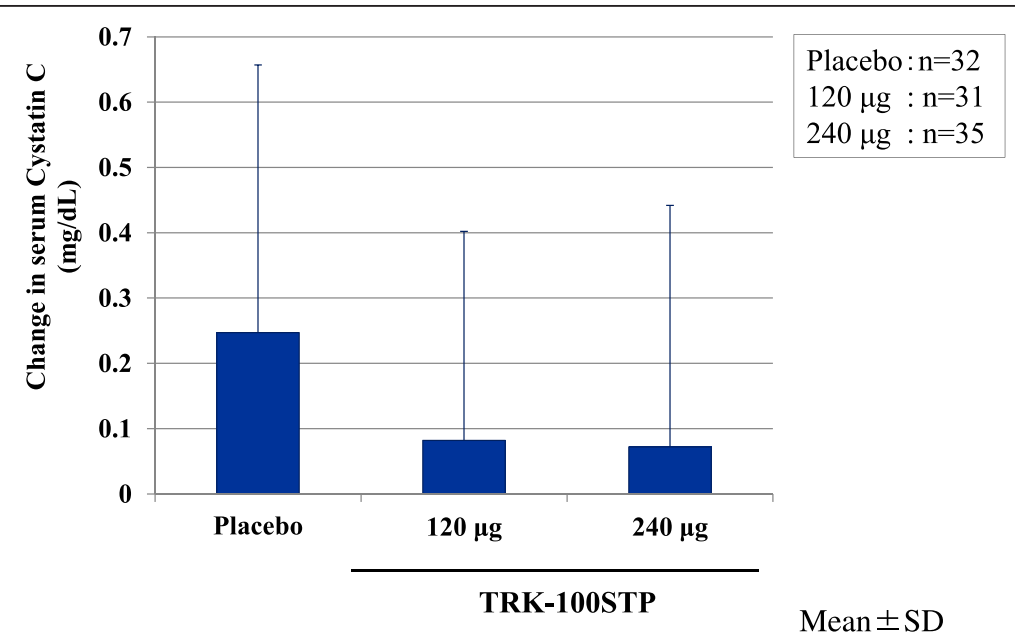

Fig. 7 Mean \pm SD of changes in serum cystatin C (final evaluation point - R20): As shown in Table 6, the 120 $\mu$ group showed a tendency and the $240 \mu \mathrm{g}$ group showed significant inhibition of the increase in change in serum cystatin $C$ as compared with the placebo group $(P=0.0928$, 0.0285 , respectively), assessed by ANCOVA with the SCr (R20) as covariate 
Table 7 Change in eGFR [the final evaluation point ${ }^{\mathrm{a}} \mathrm{NO}$ (week 0 of the treatment period)] analyzed by the ANCOVA model

\begin{tabular}{|c|c|c|c|c|c|c|}
\hline \multirow[t]{2}{*}{$\begin{array}{l}\text { Treatment } \\
\text { group }\end{array}$} & \multirow[t]{2}{*}{$\begin{array}{l}\text { Number } \\
\text { of } \\
\text { patients }\end{array}$} & \multicolumn{2}{|c|}{$\begin{array}{l}\text { Least square mean } \\
\text { of the difference in } \\
\text { serum cystatin } C \\
(\mathrm{mg} / \mathrm{L})\end{array}$} & \multicolumn{2}{|c|}{$\begin{array}{l}\text { Difference in the } \\
\text { least square mean } \\
\text { (versus placebo) } \\
\text { (mg/L) }\end{array}$} & \multirow[t]{2}{*}{ P-value } \\
\hline & & $\begin{array}{l}\text { Point } \\
\text { estimate }\end{array}$ & SE & $\begin{array}{l}\text { Point } \\
\text { estimate }\end{array}$ & SE & \\
\hline Placebo & 34 & 0.877 & 0.025 & - & - & - \\
\hline $120 \mu \mathrm{g}$ & 32 & 0.952 & 0.026 & 0.075 & 0.036 & 0.0365 \\
\hline $240 \mu \mathrm{g}$ & 36 & 0.942 & 0.024 & 0.065 & 0.035 & 0.0628 \\
\hline
\end{tabular}

${ }^{a}$ At Week 28 of the treatment period or when treatment was discontinued

(c) Post hoc analysis

Ratio of SCr (final evaluation point/WO)

As shown in Table 5 and Fig. 6, both the $120 \mu \mathrm{g}$ and the $240 \mu \mathrm{g}$ groups showed a significant inhibition of the increase in $\mathrm{SCr}$ ratios as compared with the placebo group.

Change in serum cystatin $C$ in treatment period (final evaluation point - R20)

As shown in Table 6 and Fig. 7, the $120 \mu \mathrm{g}$ group showed a tendency and the $240 \mu \mathrm{g}$ groups showed significant inhibition of the increase in change in serum cystatin $\mathrm{C}$ as compared with the placebo group.

\section{Ratio of eGFR}

As shown in Table 7, the $240 \mu \mathrm{g}$ group showed a tendency and the $120 \mu \mathrm{g}$ groups showed significant inhibition of the decrease in eGFR ratios as compared with the placebo group.

\section{Safety and tolerability}

The safety analysis was conducted based on any AEs reported during the study period. The incidence of AEs are summarized in Table 8. Two death were observed in this study; they occurred during the run-in period and so any causal relationships with the study drug was excluded.

The incidence of ADRs are summarized in Table 9. All of these ADRs cases were mild to moderate in severity, and recovered without treatment. Two serious adverse drug reactions (SADR) of cardiac failure and acute myocardial infarction were observed in the $120 \mu$ g group after randomization and both patients recovered.
The AEs and ADRs that occurred at an incidence of $5 \%$ or more are summarized in Table 10. The severity of headache in ADR was as follows: moderate headache was reported in 1 patient in the $240 \mu \mathrm{g}$ group; mild headache was reported in 1 patient in the $120 \mu \mathrm{g}$ group, and 5 patients in the $240 \mu \mathrm{g}$ group. All of these patients recovered without treatment. For clinical laboratory tests, vital signs, body weight and 12-lead ECG, no specific concerns were observed. TRK-100STP did not have significant effect on blood pressure at any dose, as detailed in Table 11.

\section{Discussion}

This is the first randomized, double-blind, placebo controlled comparative trial of TRK-100STP to investigate the possible therapeutic dose of TRK-100STP in CKD patients with a primary disease of glomerular disease or nephrosclerosis.

In the FAS, statistical superiority of the $240 \mu \mathrm{g}$ group over the placebo could not be confirmed by the primary endpoint, and so the putative recommended dose could not be clearly determined. One of the reasons why statistically significant superiority could not be confirmed was the trial lost statistical power due to the fact that more patients than had been expected were withdrawn from the study during the run-in period. As we needed to consider the feasibility of study completion, we could not secure the sufficient number of patients for analysis.

This is considered to be because the pace at which the decline in renal function became slower during the runin period. As shown in Table 3, 1/SCr versus time slope in the treatment period was ameliorated even in the placebo group. In this trial, the CKD patients who progressed and whose $1 / \mathrm{SCr}$ versus time slopes were $\leq$ $-0.005 \mathrm{dL} / \mathrm{mg}$ over 4 weeks were selected at the start of the treatment period. As a result, the number of patients to be enrolled was reduced to about $1 / 3$ of patients who had been screened. It is thought that such selection of patients also led to the regression toward the mean in all groups. This amelioration in the $1 / \mathrm{SCr}$ versus time slope in the placebo group may have made it difficult to detect the difference between the placebo group and the $240 \mu \mathrm{g}$ group in terms of the primary endpoint. However, our trial showed, for the first time, that TRK100STP might prevent the decline of renal function.

Table 8 Summary of the incidence of adverse events

\begin{tabular}{|c|c|c|c|}
\hline Parameter & $120 \mu \mathrm{g}$ & $240 \mu \mathrm{g}$ & Placebo \\
\hline Number of patients evaluated & 36 & 41 & 35 \\
\hline Number of patients who experienced adverse events & $27(75.0 \%)$ & $36(87.8 \%)$ & $28(80.0 \%)$ \\
\hline Number of patients who experienced serious adverse events & $3(8.3 \%)$ & $4(9.8 \%)$ & $1(2.9 \%)$ \\
\hline Number of patients who discontinued the study treatment due to adverse events & $4(11.1 \%)$ & $7(17.1 \%)$ & $0(0.0 \%)$ \\
\hline Number of patients who interrupted the study treatment due to adverse events & 0 (0.0 \%) & $2(4.9 \%)$ & 0 (0.0 \%) \\
\hline
\end{tabular}


Table 9 Summary of adverse drug reaction incidence

\begin{tabular}{|c|c|c|c|}
\hline Parameter & $120 \mu \mathrm{g}$ & $240 \mu \mathrm{g}$ & Placebo \\
\hline Number of patients evaluated & 36 & 41 & 35 \\
\hline Number of patients who experienced ADR & $7(19.4 \%)$ & $13(31.7 \%)$ & $5(14.3 \%)$ \\
\hline Number of patients who experienced serious ADR & $2(5.6 \%)$ & $0(0.0 \%)$ & $0(0.0 \%)$ \\
\hline Number of patients who discontinued the study treatment due to ADR & $3(8.3 \%)$ & $5(12.2 \%)$ & $0(0.0 \%)$ \\
\hline Number of patients who interrupted the study treatment due to ADR & $0(0.0 \%)$ & $1(2.4 \%)$ & $0(0.0 \%)$ \\
\hline
\end{tabular}

(): Incidence rate

This conclusion was supported by the following facts: both active study drug treatment groups exhibited better efficacy than the placebo group, and the efficacy was particularly high in the $120 \mu \mathrm{g}$ group on the primary endpoint. In the secondary endpoint analysis, both TRK100STP groups showed improvements on each of the renal filtration function parameters evaluated $(1 / \mathrm{SCr}$ versus time slope, change in the $\mathrm{CCr}$, ratio of $\mathrm{SCr}$, and change in serum cystatin C). Among them, a significant improvement was observed in the slope for $1 / \mathrm{SCr}$ versus time when contrast coefficients $[-1,1,0]$ were used, suggesting a valid hypothesis that the improvement in $120 \mu \mathrm{g}$ group was remarkable. In addition, in the post-hoc analysis, a significant improvement in the ratio of $\mathrm{SCr}$ was achieved in the $120 \mu \mathrm{g}$ group as well as in the $240 \mu \mathrm{g}$ group. The difference in cystatin C levels in the treatment period also improved in the $240 \mu \mathrm{g}$ group. Regarding the eGFR ratio, a significant improvement was observed only in the $120 \mu \mathrm{g}$ group.

Significant effects on blood pressure or urinary protein levels were not observed in this study, and thus the mechanisms of action of BPS are thought to be different from those of existing agents such as ACEIs and ARBs. Since the majority of patients in this study was taking ACEIs and/or ARBs, TRK-100STP may be a useful for treatment of CKD patients in combination with ACEIs or ARBs. TRK-100STP was considered to be well tolerated. Most of the AEs observed in this study were similar types of the events caused by prostacyclin and its analogue.

Several important limitations to this study are apparent: as the treatment period was comparatively short (28 weeks) for evaluating the decrease in the renal function, the enrollment to the trial was restricted to those patients whose renal function had progressively declined. In addition, no dialysis or doubling of $\mathrm{SCr}$ was observed during the study period so that its efficacy on the renal composite endpoint including dialysis was unclear. Further evaluation in a longer study period will therefore be necessary in future.

Based on the findings of this trial, we have further been conducting a phase IIb/III trial, CASSIOPEIR (CRF Asian Study with Oral $\mathbf{P G I}_{2}$ derivative for Evaluating Improvement of Renal function) [42]. This new trial will enroll patients who have more severe disease than those enrolled in this trial in order to ensure that a sufficient

Table 10 Adverse events and adverse drug reactions with an incidence of $5 \%$ or more

\begin{tabular}{|c|c|c|c|c|c|}
\hline \multicolumn{6}{|l|}{ Adverse Events } \\
\hline \multicolumn{2}{|l|}{$120 \mu \mathrm{g}$} & \multicolumn{2}{|l|}{$240 \mu \mathrm{g}$} & \multicolumn{2}{|l|}{ Placebo } \\
\hline Headache & $5(13.9 \%)$ & Nasopharyngitis & $11(26.8 \%)$ & Nasopharyngitis & $8(22.9 \%)$ \\
\hline Nasopharyngitis & $4(11.1 \%)$ & Headache & $7(17.1 \%)$ & Pruritus & $3(8.6 \%)$ \\
\hline Back pain & $3(8.3 \%)$ & Diarrhea & $5(12.2 \%)$ & Fever & $3(8.6 \%)$ \\
\hline Hyperkalemia & $2(5.6 \%)$ & Malaise & $3(7.3 \%)$ & Hyperkalemia & $3(8.6 \%)$ \\
\hline Dizziness & $2(5.6 \%)$ & & & Influenza & $2(5.7 \%)$ \\
\hline Hypertension & $2(5.6 \%)$ & & & Hyperkalemia & $2(5.7 \%)$ \\
\hline Upper respiratory tract inflammation & $2(5.6 \%)$ & & & Muscle Spasm & $2(5.7 \%)$ \\
\hline Diarrhea & $2(5.6 \%)$ & & & Genital Bleeding & $2(5.7 \%)$ \\
\hline Vomiting & $2(5.6 \%)$ & & & & \\
\hline Arthralgia & $2(5.6 \%)$ & & & & \\
\hline \multicolumn{6}{|l|}{ Adverse drug reactions } \\
\hline $120 \mu \mathrm{g}$ & & $240 \mu \mathrm{g}$ & & Placebo & \\
\hline \multirow[t]{2}{*}{ Hypertension } & $2(5.6 \%)$ & Headache & $6(14.6 \%)$ & Genital Bleeding & $2(5.7 \%)$ \\
\hline & & Malaise & 3 (7.3 \%) & & \\
\hline
\end{tabular}

(): Incidence rate 
Table 11 Effect of TRK-100STP $120 \mu \mathrm{g}$ and $240 \mu \mathrm{g}$ on blood pressure

\begin{tabular}{|c|c|c|c|c|c|}
\hline \multicolumn{2}{|c|}{ Treatment group } & \multicolumn{2}{|c|}{ Systolic blood pressure } & \multicolumn{2}{|c|}{ Diastolic blood pressure } \\
\hline & & R20 & Final evaluation point & R20 & Final evaluation point \\
\hline \multirow[t]{2}{*}{ Placebo } & No. of patients & 35 & 35 & 35 & 35 \\
\hline & Mean \pm SD & $123.8 \pm 17.0$ & $127.5 \pm 20.3$ & $72.7 \pm 10.9$ & $75.3 \pm 9.9$ \\
\hline \multirow[t]{2}{*}{$120 \mu g$} & No. of patients & 36 & 35 & 36 & 35 \\
\hline & Mean \pm SD & $128.3 \pm 13.0$ & $127.8 \pm 13.5$ & $73.6 \pm 10.7$ & $75.4 \pm 10.5$ \\
\hline \multirow[t]{2}{*}{$240 \mu \mathrm{g}$} & No. of patients & 41 & 40 & 41 & 40 \\
\hline & Mean \pm SD & $128.3 \pm 16.4$ & $129.4 \pm 13.7$ & $74.4 \pm 10.6$ & $75.1 \pm 8.9$ \\
\hline
\end{tabular}

(Unit of blood pressure: $\mathrm{mmHg}$ )

number of clinical events can be observed within a designated time period, using renal composite endpoints to evaluate treatment outcome. This trial will also be dosefinding as it utilizes the same two doses as used in this study. The trial is being conducted in seven Asian countries, including Japan.

\section{Conclusions}

Although this randomized, placebo-controlled, doubleblind, comparative trial failed to meet the primary endpoint to determine the recommended dose for the treatment of patients with CKD with primary glomerular disease or nephrosclerosis, it shows for the first time, that TRK100STP might potentially prevent the decline in renal function of such patients, independent of blood pressure or urinary protein levels. These findings have helped in the design and conduct of the ongoing phase IIb/III trial, CASSIOPEIR.

\section{Additional file}

Additional file 1: CONSORT 2010 Flow Diagram. (DOC $37 \mathrm{~kb}$ )

\begin{abstract}
Abbreviations
ACEls: Angiotensin-converting enzyme inhibitors; ADR: Adverse drug reaction; AE: Adverse event; ANCOVA: Analysis of covariance; ARB: Angiotensin-II receptor blocker; BPS: Beraprost sodium; CASSIOPEIR: CRF Asian Study with Oral PGI derivative for Evaluating Improvement of Renal function; CCr: Creatinine clearance; CKD: Chronic kidney disease; CRF: Chronic renal failure; ECG: Electrocardiogram; ESRD: End-stage renal disease; FAS: Full analysis set; NSAIDs: Nonsteroidal anti-inflammatory drugs; $\mathrm{PGI}_{2}$ : Prostaglandin $\mathrm{I}_{2}$ (also called prostacyclin); PPS: Per protocol set; RAS: Renin-angiotensin system;

SADR: Serious adverse drug reactions; SCr: Serum creatinine.

\section{Competing interests}

AK and FG have no conflict of interest. TF and $\mathrm{HO}$ serve as a consultant of Toray. TF is a recipient of grants for Astellas, Toray, Boehringer Ingelheim, Chugai, Fukuda Denshi, Kyowa Hakko Kirin, Mitsubishi Tanabe, Mochida, Omron, Pfizer and Takeda. Also, TF is a recipient of lecture fee for Astellas, Boehringer Ingelheim, Kyowa Hakko Kirin, Mitsubishi Tanabe, Daiichi Sankyo, Novartis, Pfizer and Takeda. MI, HAKU and KO are employees of Toray, while HIKA, TK and SY are employees of Astellas.
\end{abstract}

\section{Authors' contributions}

AK, TF and FG were assigned as medical advisors for the study but their terms of duty were all different during the study period. They were involved in the conception and design of the study, and advisers for conducting the study. $\mathrm{HO}$ was involved in the conception and study design and provided statistical support of the study. MI, HAKU, KO, HIKA, TK and SY were involved in the study conception and acquisition of data and data analysis. AK and HAKU wrote the draft of the manuscript. All authors critically reviewed the manuscript and approved the final manuscript as submitted.

\section{Acknowledgements}

This trial was sponsored by Toray Industries, Inc. and Astellas Pharma Inc. in the design, and in the collection and analysis of the data.

We would like to thank the doctors, nurses and staff at the sites listed below for their participation and assistance in the trial. We also thank Osamu Hotta and Takayuki Fujita for their important suggestion about the design of the protocol and thank Yoshitaka Mori, Takeshi Matsugi and all other members of Toray and Astellas for the participation in the trial. We would like to thank Midori Ogasawara and Satoshi Henmi of Toray, Hirotoshi Kakuta, Tomihisa Kawasaki and Hiroyuki Okumura of Astellas and Jun Kishi of MEDCORE ASSOCIATES Inc., for having provided their assistance in the preparation of the report.

\section{Participating centers}

Aizawa Hospital, Akebono Hospital, Anjo Kosei Hospital, Asahi Chuo Hospital, Chiba Seikatsu-shukanbyo Internal Medicine Clinic, Chubu Rosai Hospital, Dainohara Medical Clinic, Fujisawa City Hospital, Fujita Health University Hospital, Fukuoka University Hospital, Hamamatsu University Hospital, Hiroshima City Hospital, Hiroshima Red Cross Hospital \& Atomic-bomb Survivors Hospital, Hitachi General Hospital, Hitachi Mito General Hospital, Hokkaido University Hospital, Ichikawa East Hospital, Japanese Red Cross Society Suwa Hospital, Jichi Medical University Hospital, Kasugai Municipal Hospital, Kawahara Clinic, Kawasaki Medical School Hospital, Kawashima Clinic, Kawashima Hospital, Kinashi Obayashi Hospital, Kinki Central Hospital of Mutual Aid Association of Public School Teachers, Kitasato Institute Hospital, Kitasato University Kitasato Institute Medical Center Hospital, Kobe City Medical Center General Hospital, Kyoto University Hospital, Medical Corporation Fukuseikai Fukuseikai Hospital, Mito Saiseikai General Hospital, Mitsubishi Kyoto Hospital, Munakata Medical Association Hospital, Nagasaki University Hospital of Medicine and Dentistry, Nagoya University Hospital, Nara Medical University Hospital, Narita Memorial Hospital, National Center for Global Health and Medicine, National Hospital Organization Disaster Medical Center, National Hospital Organization Kanazawa Medical Center, National Hospital Organization Kure Medical Center, National Hospital Organization Nagasaki Medical Center, National Hospital Organization Oita Medical Center, National Hospital Organization Osaka National Hospital, National Hospital Organization Shizuoka Medical Center, National Kyushu Medical Center, Nihon University Itabashi Hospital, Niigata Rinko Hospital, Niigata University Medical \& Dental Hospital, NTT Medical Center Tokyo, Ohno Memorial Hospital, Okabe Hospital, Okayama Medical Center, Okayama University Hospital, Okazaki City Hospital, Osaka General Medical Center, Osaka Red Cross Hospital, Osaka University Hospital, Rinku General Medical Center, Saiki kidney clinic, Saiseikai Niigata Daini Hospital, Saiseikai Yokohamasi Nanbu Hospital, Saitama Medical University Hospital, Sakai Rumi Clinic, Sanjou General Hospital, Seirei Hamamatsu General Hospital, Sendai Shakaihoken Hospital, Shimazu Hospital, Shinrakuen Hospital, Shinshu University Hospital, Shonan Kamakura General Hospital, Showa University Fujigaoka Hospital, Social Insurance Chuo General Hospital, St. Marianna University School of Medicine Hospital, Sunagawa City Medical Center, Takayama Hospital, Tanaka Kitanoda Hospital, The University of Tokyo Hospital, Toho University Omori Medical Center, Tokai University Hospital, Tokuyama Central Hospital, Tokyo Kyosai Hospital, Tokyo Medical 
University Hospital, Tokyo Medical University Ibaraki Medical Center, Tosei General Hospital, Toyota Memorial Hospital, Tsuchiya General Hospital, Tsukuba Central Hospital, Tsukuba University Hospital, Ureshino Medical Center, Yokohama City Minato Red Cross Hospital, Yokohama City University Medical Center, Yokohama Minami Kyousai Hospital, Yonago Medical Center. (Alphabetical order).

\section{Author details \\ 'University of Tsukuba, 1-1-1 Tennodai, Tsukuba, Ibaraki 305-8577, Japan. ${ }^{2}$ Division of Clinical Epigenetics, Research Center for Advanced Science and Technology, The University of Tokyo, 4-6-1 Komaba, Meguro-ku, Tokyo 153-8904, Japan. ${ }^{3}$ Niigata University, 1-757, Asahimachi-dori, Chuo-ku, Niigata 951-8510, Japan. ${ }^{4}$ Division of Biostatistics and Clinical Epidemiology, Graduate School of Medicine and Pharmaceutical Sciences, The University of Toyama, 2630 Sugitani, Toyama City 930-0194, Japan. ${ }^{5}$ Toray Industries, Inc., 1-1, Nihonbashi-Muromachi 2-chome, Chuo-ku, Tokyo 103-8666, Japan. ${ }^{6}$ Astellas Pharma Inc., 2-5-1 Nihonbashi-honcho, Chuo-ku, Tokyo 103-8411, Japan.}

Received: 23 January 2015 Accepted: 28 July 2015

Published online: 16 October 2015

\section{References}

1. Xie $Y$, Chen X. Epidemiology, major outcomes, risk factors, prevention and -management of chronic kidney disease in China. Am J Nephrol. 2008;28:1-7

2. Akizawa T. Current Status of Dialysis Therapy and Related Clinical Guidelines in Japan. JMAJ. 2010;53:185-7.

3. Hwang SJ, Tsai JC, Chen HC. Epidemiology, impact and preventive care of chronic kidney disease in Taiwan. Nephrology (Carlton). 2010;15 Suppl 2:3-9.

4. Jin DC. Current status of dialysis therapy in Korea. Korean J Intern Med. 2011;26:123-31.

5. KDIGO. KDIGO 2012 clinical practice guideline for the evaluation and management of chronic kidney disease. Kid Int. 2013;3:1-150.

6. ONTARGET Investigators, Yusuf S, Teo KK, Pogue J, Dyal L, Copland I, et al. Telmisartan, ramipril, or both in patients at high risk for vascular events. $\mathrm{N}$ Engl J Med. 2008;358:1547-59.

7. Imai E, Chan JC, Ito S, Yamasaki T, Kobayashi F, Haneda M, et al. Effects of olmesartan on renal and cardiovascular outcomes in type 2 diabetes with overt nephropathy: a multicentre, randomised, placebo-controlled study. Diabetologia. 2011;54:2978-86.

8. Fried LF, Emanuele N, Zhang JH, Brophy M, Conner TA, Duckworth W, et al. Combined angiotensin inhibition for the treatment of diabetic nephropathy. N Engl J Med. 2013;369:1892-903.

9. Parving HH, Brenner BM, McMurray JJ, de Zeeuw D, Haffner SM, Solomon $\mathrm{SD}$, et al. Cardiorenal end points in a trial of aliskiren for type 2 diabetes. $\mathrm{N}$ Engl J Med. 2012;367:2204-13.

10. Moncada S, Gryglewski R, Bunting S, Vane JR. An enzyme isolated from arteries transforms prostaglandin endoperoxidases to an unstable substance that inhibits platelet aggregation. Nature. 1976;263:663-5.

11. Yokoyama C, Yabuki T, Shimonishi M, Wada M, Hatae T, Ohkawara S, et al. Prostacyclin-deficient mice develop ischemic renal disorders, including nephrosclerosis and renal infarction. Circulation. 2002;106:2397-403.

12. Spargias K, Adreanides E, Demerouti E, Gkouziouta A, Manginas A, Pavlides $\mathrm{G}$, et al. Iloprost prevents contrast-induced nephropathy in patients with renal dysfunction undergoing coronary angiography or intervention. Circulation. 2009;120:1793-9.

13. Ohno K, Nagase H, Matsumoto K, Nishiyama H, Nishio S. Stereoselective synthesis of 5,6,7-trinor-4,8-inter-m-phenylene-PG| ${ }_{2}$ derivatives and their inhibitory activities to human platelet aggregation. Adv Prostaglandin Thromboxane Leukot Res. 1985;15:279-81.

14. Kurumatani H. Pharmacological profiles and clinical effects of oral sustained release beraprost sodium (Careload LA tablets $60 \mu \mathrm{g}$, Berasus LA tablets $60 \mu \mathrm{g})$. Nihon Yakurigaku Zasshi. 2009;133:101-11.

15. Nagaya N. Orally active prostacyclin analogue for cardiovascular disease. Int Angiol. 2010;29(2 Suppl):14-8

16. Fine LG, Bandyopadhay D, Norman JT. Is there a common mechanism for the progression of different types of renal diseases other than proteinuria?
Towards the unifying theme of chronic hypoxia. Kidney Int Suppl. 2000;75:S22-6.

17. Eckardt KU, Bernhardt WM, Weidemann A, Warnecke C, Rosenberger C, Wiesener MS, et al. Role of hypoxia in the pathogenesis of renal disease. Kidney Int Suppl. 2005;99:S46-51.

18. Kang DH, Kanellis J, Hugo C, Truong L, Anderson S, Kerjaschki D, et al. Role of the microvascular endothelium in progressive renal disease. J Am Soc Nephrol. 2002;13:806-16.

19. Nangaku M. Chronic hypoxia and tubulointerstitial injury: a final common pathway to end-stage renal failure. J Am Soc Nephrol. 2006;17:17-25.

20. Inoue T, Kozawa E, Okada H, Inukai K, Watanabe S, Kikuta T, et al. Noninvasive evaluation of kidney hypoxia and fibrosis using magnetic resonance imaging. J Am Soc Nephrol. 2011;22:1429-34.

21. Utsunomiya Y, Ogura M, Kawamura T, Mitarai T, Maruyama N, Sakai O. Attenuation of immune complex nephritis in NZB/WF1 mice by a prostacyclin analogue. Clin Exp Immunol. 1995;99:454-60.

22. Kushiro M, Shikata K, Sugimoto H, Shikata Y, Miyatake N, Wada J, et al. Therapeutic effects of prostacyclin analog on crescentic glomerulonephritis of rat. Kidney Int. 1998;53:1314-20.

23. Yamada M, Sasaki R, Sato N, Suzuki M, Tamura M, Matsushita T, et al. Amelioration by beraprost sodium, a prostacyclin analogue, of established renal dysfunction in rat glomerulonephritis model. Eur J Pharmacol. 2002:449:167-76

24. Yamaguchi S, Inada C, Tamura M, Sato N, Yamada M, Itaba S, et al. Beraprost sodium improves survival rates in anti-glomerular basement membrane glomerulonephritis and 5/6 nephrectomized chronic kidney disease rats. Eur J Pharmacol. 2013;714:325-31.

25. Yamaguchi S, Goto Y, Sato N, Kurumatani H, Miymoto M, Yamada M Beraprost sodium suppresses progression of chronic renal failure by protecting renal capillary endothelial cells and improving renal hypoxia in glomerulonephritis rats. J Am Soc Nephrol. 2013;24:868A.

26. Goto Y, Yamaguchi S, Tamura M, Mochizuki H, Kurumatani H, Okano K, et al. A prostacyclin analog prevents the regression of renal microvascular network by inhibiting mitochondria-dependent apoptosis in the kidney of rat progressive glomerulonephritis. Prostaglandins Other Lipid Mediat. 2014;112:16-26.

27. Mishima K, Baba A, Matsuo M, Itoh Y, Oishi R. Protective effect of cyclic AMP against cisplatin-induced nephrotoxicity. Free Radic Biol Med. 2006;40:1564-77.

28. Itoh Y, Yano T, Sendo T, Oishi R. Clinical and experimental evidence forprevention of acute renal failure induced by radiographic contrast media. J Pharmacol Sci. 2005:97:473-88.

29. Sakai A, Yajima M, Nishio S. Cytoprotective effect of TRK-100, a prostacyclin analogue, against chemical injuries in cultured human vascular endothelial cells. Life Sci. 1990:47:711-9.

30. Tamura M, Kurumatani H, Matsushita T. Comparative effects of beraprost, a stable analogue of prostacyclin, with PGE(1), nitroglycerin and nifedipine on canine model of vasoconstrictive pulmonary hypertension. Prostaglandins Leukot Essent Fatty Acids. 2001;64:197-202.

31. Nishio $S$, Matsuura $H$, Kanai $N$. The in vitro and ex vivo antiplatelet effect of TRK-100, a stable prostacyclin analog, in several species. Jpn J Pharmacol. 1988;47:1-10.

32. Fujita $T$, Fuke $Y$, Satomura $A$, Hidaka $M$, Ohsawa I, Endo $M$, et al. $P \mathrm{G}_{2}$ analogue mitigates the progression rate of renal dysfunction improving renal blood flow without glomerular hyperfiltration in patients with chronic renal insufficiency. Prostaglandins Leukot Essent Fatty Acids. 2001;65:223-7.

33. Ishida A, Hotta O, Takuma T. Clinical efficacy of $\mathrm{PG}_{2}$ derivative (BPS) in patients with progressive renal disease. Jpn J Nephrol. 2003;45:276.

34. Owada A, Suda S, Hata T. Effect of long-term administration of prostaglandin $\mathrm{I}_{2}$ in incipient diabetic nephropathy. Nephron. 2002;92:788-96.

35. Wang LN, Tang Z, Shou I, Fukui M, Tomino Y. Effects of the $P G I_{2}$ analog beraprost sodium on glomerular prostanoid synthesis in rats with streptozotocin-induced diabetes. Nephron. 1996;73:637-43.

36. Watanabe M, Nakashima $H$, Mochizuki S, Abe $Y$, Ishimura A, Ito $K$, et al. Amelioration of diabetic nephropathy in OLETF rats by prostaglandin $I_{2}$ analog, beraprost sodium. Am J Nephrol. 2009;30:1-11.

37. Sato N, Kaneko M, Tamura M, Kurumatani $H$. The prostacyclin analog beraprost sodium ameliorates characteristics of metabolic syndrome in obese Zucker (fatty) rats. Diabetes. 2010;59:1092-100. 
38. Mitch WE, Walser M, Buffington GA, Lemann Jr J. A simple method of estimating progression of chronic renal failure. Lancet. 1976;2(7999):1326-8.

39. Brenner BM, Cooper ME, de Zeeuw D, Keane WF, Mitch WE, Parving HH, et al. Effects of losartanon renal and cardiovascular outcomes in patients with type 2 diabetes andnephropathy. N Engl J Med. 2001;345:861-9.

40. Koide K, Koshikawa S, Yamane Y. Clinical evaluation of AST-120 on suppression of progression of chronic renal failure. Multi-center, double-blind study in comparison with placebo. Clin Eval. 1987;15:527-64.

41. Matsuo S, Imai E, Horio M, Yasuda Y, Tomita K, Nitta K, et al. Collaborators developing the Japanese equation forestimated GFR. Revised equations for estimated GFR from serum creatinine in Japan. Am J Kidney Dis. 2009:53:982-92.

42. Nakamoto H, Fujita T, Origasa H, Isono M, Kurumatani H, Okada K, et al. A multinational phase Ilb/III trial of beraprost sodium, an orally active prostacyclin analogue, in patients with primary glomerular disease or nephrosclerosis (CASSIOPEIR trial), rationale and study design. BMC Nephrol. 2014;15:153

\section{Submit your next manuscript to BioMed Central and take full advantage of:}

- Convenient online submission

- Thorough peer review

- No space constraints or color figure charges

- Immediate publication on acceptance

- Inclusion in PubMed, CAS, Scopus and Google Scholar

- Research which is freely available for redistribution 